$\begin{array}{ll} & \text { Etnográfica } \\ \text { etnográfica } & \text { Revista do Centro em Rede de Investigação em }\end{array}$

Antropologia

vol. $19(3) \mid 2015$

Vol. $19(3)$

\title{
Mediações do cuidado no âmbito do Programa Saúde da Família em Itaparica, Brasil
}

Mediated care in a public program for family health in Itaparica, Brazil

Fátima Tavares, Carlos Caroso e Carolina Santana

\section{(2) OpenEdition}

Journals

\section{Edição electrónica}

URL: https://journals.openedition.org/etnografica/4085

DOI: 10.4000/etnografica.4085

ISSN: 2182-2891

\section{Editora}

Centro em Rede de Investigação em Antropologia

\section{Edição impressa}

Data de publição: 1 outubro 2015

Paginação: 489-513

ISSN: 0873-6561

\section{Refêrencia eletrónica}

Fátima Tavares, Carlos Caroso e Carolina Santana, «Mediações do cuidado no âmbito do Programa Saúde da Família em Itaparica, Brasil», Etnográfica [Online], vol. 19 (3) | 2015, posto online no dia 27 outubro 2015, consultado o 11 fevereiro 2022. URL: http://journals.openedition.org/etnografica/4085 ; DOI: https://doi.org/10.4000/etnografica.4085

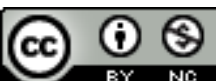

Etnográfica is licensed under a Creative Commons Attribution-NonCommercial 4.0 International License. 


\section{Mediações do cuidado no âmbito do Programa Saúde da Família em Itaparica, Brasil}

\section{Fátima Tavares, Carlos Caroso e Carolina Santana}

A partir da etnografia sobre o cotidiano dos profissionais de saúde que atuam no âmbito do Programa ou Estratégia Saúde da Família (sistema público de atenção básica à saúde) no município de Itaparica, busca-se problematizar as abordagens sobre a diversidade terapêutica que partem de premissas dualísticas como tradicional e moderno ou oficial e alternativo. Nesse intento, são apresentados alguns dilemas da prática cotidiana dos profissionais de saúde, considerando a diversidade terapêutica com a qual aqueles se confrontam em seu cotidiano. Na conclusão, sugere-se que os conflitos que intermediam a assimetria na convivência entre diferentes práticas terapêuticas no âmbito desse sistema são indicativos de desacordos mais amplos, que podem ser identificados nas intenções "civilizatórias" de transformação dos modos de vida das populações atendidas por programas públicos de assistência à saúde.

PALAVRAS-CHAVE: Estratégia Saúde da Família, antropologia da saúde, diversidade terapêutica, terapêuticas comunitárias, religiões, Brasil.

Mediated care in a public program for family health in Itaparica, Brazil - Based on the ethnography of daily life of health professionals who work in the "Family Health Program" (public system of basic health care) in the city of Itaparica, this article addresses therapeutic approaches to diversity departing from dualistic assumptions as traditional/modern or official/alternative. In this attempt, some of the daily dilemmas in the practice of health professionals are examined, taking into account the therapeutic diversity that they have to deal with. It is suggested that the conflicts that mediate the asymmetry in the coexistence of different therapeutic practices in this system are indicative of broader disagreements, which may be identified on the "civilizing" intentions of transformation of the lifeways of the populations assisted by public health care programs.

KEYWORDS: Family Health Program, anthropology of health, therapeutic diversity, community therapies, religions, Brazil.

TAVARES, Fátima (fattavares@ufba.br) - Departamento de Antropologia, UFBA, ObservaBaía, Brasil.

CAROSO, Carlos (caroso@ufba.br) - Departamento de Antropologia, UFBA, ObservaBaía, Brasil.

SANTANA, Carolina (carolinasantana_1@hotmail.com) - Pós-Graduação em Antropologia, UFBA, ObservaBaía, Brasil. 
NESTE ARTIGO SÃO PROBLEMATIZADAS PREMISSAS DUALÍSTICAS COMO tradicional e moderno ou oficial e alternativo enquanto referentes terapêuticos excludentes. ${ }^{1}$ Ao invés de premissas, a ideia é focar em processos, não seguindo apressadamente pelos atalhos convidativos de conceitos que pretensamente "desvendam" forças ou tendências e que se tornam capazes de explicar tudo, mas seguir de perto a vivacidade característica das situações de pesquisa.

A realização de um estudo etnográfico sobre o Programa Saúde da Família (ou Estratégia Saúde da Família, doravante denominada ESF) no município de Itaparica resultou nos dados que são analisados neste artigo, e particularmente nos permite buscar estabelecer um diálogo com a proposta de Latour (2006) de investigar as mediações que refazem constantemente os contornos do "social". ${ }^{2}$ A aproximação daquela proposta permite compreender como a ESF é atravessada por uma heterogeneidade de práticas de cuidado, conformando um espaço de multiplicidades em que o "antigo" e o "novo" convivem e se influenciam mutuamente. Esse dinamismo promove uma nova configuração do espaço público de mediações terapêuticas que desafiam os dispositivos de hierarquização e controle envolvidos nos processos de territorialização desse sistema de saúde.

Ao longo da discussão apresentamos alguns dilemas da prática cotidiana dos profissionais de saúde da ESF e da diversidade terapêutica com que eles têm que lidar. ${ }^{3}$ Argumentamos que, embora essa diversidade não configure um sistema estruturado, alternativo ou concorrente ao oficial, ainda assim, as formas de convivência constituem importantes desafios para o sucesso das políticas públicas de saúde. Finalizamos sugerindo que os conflitos que intermedeiam a assimetria na convivência entre diferentes práticas terapêuticas no âmbito da ESF nos parecem indicativos de desacordos mais amplos das intenções "civilizatórias" de transformação dos "modos de vida" das populações atendidas.

l Uma versão inicial deste artigo foi apresentada no XXXV Convegno Internazionale di Americanistica. A versão atual é ampliada, além de apresentar algumas alterações decorrentes das sugestões dos pareceristas.

2 A ESF foi anteriormente designada Programa Saúde da Família (PSF), nome pelo qual ainda hoje é amplamente conhecida. A ESF organiza o sistema público de atenção básica à saúde atualmente disseminado pelo país; os recursos financeiros são dotados pelo governo federal e a gestão é de competência dos municípios. Organiza-se na forma de equipes de saúde, que são responsáveis por territórios delimitados no âmbito dos limites municipais.

3 A pesquisa priorizou as entrevistas com os agentes comunitários de saúde (ACS) e, em menor escala, com enfermeiros. Quanto aos médicos, apenas um foi entrevistado. Esse desenho decorre das dificuldades, entre enfermeiros e médicos, de se conseguir algum espaço nas agendas para a realização de entrevistas. Já com os ACS é sempre possível realizar conversas e entrevistas acompanhando seu trabalho nas visitas domiciliares ou em horários alternativos à noite e nos finais de semana. Essa "restrição" na coleta de dados junto aos profissionais da saúde certamente produz algumas perspectivas de abordagens dos dilemas do trabalho cotidiano que transcendem o espaço físico das unidades básicas de saúde (UBS) e que nos interessa desenvolver aqui. 


\section{DILEMAS DO CUIDADO NA ESF}

Nas pesquisas em antropologia da saúde, ${ }^{4}$ um falso dilema reside na abordagem da heterogeneidade terapêutica como um enfrentamento entre mundos estanques e irreconciliáveis: o setor comunitário em saúde (saberes terapêuticos tradicionais, populares, religiosos) e o setor profissional em saúde (biomedicina, terapias alternativas, complementares, paralelas). Diferenças existem entre saberes tradicionais e modernos e podem ser verificadas não apenas nos seus resultados, mas também nos "modos de fazer". Mas nada mais impróprio do que tratá-las nos termos dicotômicos da imaginação ocidental, onde o tradicional traduz-se na substantividade de algo imemorial, estático e a ser entesourado por avalistas do "autêntico", por oposição ao moderno, sempre aberto à reflexividade e mudança (Cunha 2009).

Alternativas a essa dicotomia podem ser encontradas numa abordagem etnográfica focalizada nos processos que envolvem profissionais da cura em suas práticas de saúde. Essa orientação possibilita a investigação dos conceitos de saúde e doença não como representações, mas enquanto agenciamentos, tal como proposto por Mol (2003). Recusando a diferença entre disease e illness, a autora propõe explorar o corpo múltiplo e suas diseases. O problema do relativismo ou das diferentes perspectivas de abordagem da doença ou do corpo é justamente o fato de que eles continuam lá, intocados, a despeito das significações (de médicos, ou pacientes, etc.) sobre eles. O passo sugerido por Mol é colocar em primeiro plano as "[...] praticalidades, materialidades, eventos. Se nós dermos esse passo, 'disease' se torna parte do que é feito na prática" (2003: 13).

Outra linha importante de investigação é a que aborda os dilemas que atravessam os programas de saúde pública, especialmente a questão do "sofrimento social" que aparece como o "preço a pagar" no enfrentamento das frustrações e como poder de justificação, nos moldes de uma "teodiceia secular" (Das 1997). Nesse contexto, deve-se destacar as contribuições de Fassin (1998) na

4 Não é intenção, neste trabalho, apresentar uma discussão pormenorizada relacionando a prática cotidiana da ESF às discussões sobre políticas públicas. Como essa tarefa extrapola os limites deste texto, faremos apenas algumas considerações. As contribuições da antropologia para a saúde podem ser pensadas a partir do trabalho de Langdon (2014), onde a autora apresenta dois eixos de análise dessas relações. O primeiro eixo, da saúde como experiência sociocultural, ancora-se em teorias norte-americanas e francesas que dialogam com a produção brasileira. O segundo eixo compreende um diálogo entre saúde e política e tem como referência a produção antropológica latino-americana. Nesse eixo são enfatizadas as abordagens interdisciplinares na compreensão dos processos de saúde e doença, problematizando a universalidade da perspectiva biomédica e chamando a atenção para os agenciamentos mobilizados por indivíduos e grupos. Podemos localizar nosso trabalho nesse conjunto de preocupações do segundo eixo apontadas pela autora, especialmente no que se refere às relações entre biomedicina e práticas de saúde locais implementadas por programas governamentais. Para uma análise dos principais desafios decorrentes das transformações recentes da antropologia médica e sua contribuição para o desenvolvimento de políticas públicas de saúde, ver Campbell (2010). A respeito da contribuição da antropologia para as abordagens sobre "saúde global”, ver Janes e Corbett (2009). 
investigação dos modos de controle e cuidado na saúde pública para populações vulneráveis e a questão dos sentimentos morais como forma de legitimação das políticas públicas (Fassin 2010). Temos, assim, políticas de saúde em resposta ao sofrimento social que se constituem de "modos morais de intervenção" para a manutenção de exclusões sociais.

Como observam Pussetti e Brazzabeni (2011), o conceito de sofrimento social tem propiciado uma articulação profícua nas investigações sobre as experiências do mal-estar e processos sociais mais abrangentes. A potencialidade desse conceito se realiza na interface de diferentes abordagens (gênero, migração, exclusão social, juventude, etc.), dentre elas as das questões de saúde pública. Como apontam os vários autores no dossiê a que Pussetti e Brazzabeni fazem referência, essas interfaces possibilitam a investigação das dimensões sociais e políticas do mal-estar, a relação entre as experiências dos sujeitos e as agendas institucionais e o posicionamento ético dos antropólogos. Assim, na medida em que o conceito de sofrimento social evidencia tensões entre sujeito e ordem social, possibilita a exploração das ambiguidades geradas no processo de implementação de políticas sociais para a sua minimização. ${ }^{5}$ Como sugerem as autoras, se trata de fazer,

"[...] por um lado, a análise das intervenções sociais para aliviar o sofrimento dos sujeitos definidos como 'vulneráveis' e que frequentemente resultam na sua intensificação; por outro, a problematização das mesmas intervenções, que classificam os sujeitos em categorias rígidas, através de mecanismos complexos de patologização, criminalização e exclusão social" (Pussetti e Brazzabeni 2011: 468).

O estudo do sofrimento social, com sua ênfase nas dimensões morais, aparece, então, como uma démarche produtiva ao problematizar questões como pobreza e exclusão social, que intervêm como condições de vulnerabilidades (incluindo-se aí as "patologias"), possibilitando articular experiências locais e processos sociais mais amplos. ${ }^{6}$ Embora em nosso trabalho não estejamos tratando de populações de risco no sentido mais estrito do termo (populações de rua ou

5 Participando do mesmo dossiê, que reúne trabalhos sobre o sofrimento social, vale destacar a abordagem de Challinor (2011) sobre o "sofrimento vulgar" em microcosmos sociais, tomando duas situações etnográficas em que se verifica a redução do eu a uma filiação social específica. São casos de sofrimento cotidiano, invisibilizados por rotinas de opressão, fazendo com que certas categorizações sociais sejam ativadas, como, por exemplo, as identidades étnicas. Esses sofrimentos contínuos produzem muitas pequenas fissuras nas relações sociais, possibilitando a sua compreensão para além da dimensão da pobreza material.

6 Sobre essas articulações vale destacar o trabalho de Li (2007) a respeito das políticas de desenvolvimento. Nele a autora se detém nas formas através das quais atores e instituições intervêm nas práticas políticas, chamando a atenção para novas modalidades de poder. 
usuários de drogas, por exemplo), a pertinência dessas reflexões evidencia-se nos dilemas morais que envolvem as tensões em torno do que propõem os programas de saúde (como é o caso da ESF) e as expectativas da população:

"A retórica da 'qualidade de vida' que informa estes programas, entendida em termos morais, além de materiais, representa a instigação contemporânea de uma intervenção destinada a uma maior inserção e realização pessoal (empowerment) das faixas vulneráveis da população. A população 'em risco' é também uma população 'de risco', que ameaça, que contagia [...]” (Pussetti e Brazzabeni 2011: 473).

No âmbito da ESF, um conjunto de princípios que envolve a "integralidade em saúde" coloca como um dos muitos desafios o de mobilizar o que chamamos aqui de "concepção ampliada do cuidado", que não é compreendido apenas como execução de procedimentos. Reformula-se o contexto onde são estabelecidas as relações entre os agentes de saúde e os usuários, procurando superar a percepção "tradicional” da prática médica que intervém sobre o indivíduo não situado (Fontes 2004).

Perseguir os processos possibilita-nos, assim, prestar mais atenção à dinâmica das práticas de cuidado que atravessam o espaço heterogêneo dos serviços de saúde na ESF. Por serem práticas que levam em consideração as redes locais em que o indivíduo está situado, estas precipitam - no sentido de Wagner (1975), como consequências não intencionais - a intensificação dos dilemas da convivência cotidiana na ESF. Os dilemas podem, inclusive, se estender para além das noções usuais do cuidado terapêutico (tecnologias de intervenção sobre os corpos), mobilizando desacordos em torno dos agenciamentos mais amplos do cuidado.

Pesquisas anteriores sobre a heterogeneidade terapêutica na ESF (Bonet e Tavares 2006, 2007, 2008; Tavares e Bonet 2008; Bonet et al. 2009) apontam muitos desafios tanto no processo de implantação como na prática cotidiana do sistema. Um problema central é o não reconhecimento da coexistência de redes de cuidado em saúde que atravessam a territorialização oficial promovida pela ESF (Deleuze e Guattari 1997). Uma primeira rede adscreve a comunidade por meio do cadastro da população residente no âmbito de atuação de uma equipe de saúde. A segunda situa cada unidade domiciliar como unidade de cadastro. Sobre essas duas redes é que se realizam as intervenções de cuidado terapêutico, embora, na prática, as equipes tenham de conviver com outras mediações que não apenas a rede comunitária mais ampla e a rede das relações familiares. ${ }^{7}$ Por outro lado, além de tensões, na área de abrangência

7 Bonet e Tavares (2006) já evidenciaram a importância das relações de vizinhança, familiares e religiosas como redes intersticiais de cuidado. 
dos módulos do sistema territorializado da ESF, também se observam formas de articulação e "convivência" de orientações e práticas em rede (Bonet e Tavares 2006). ${ }^{8}$

É assim que, na diversidade terapêutica da ESF, a legitimidade social das redes de cuidado é dinâmica e assimétrica, podendo as mediações envolver processos de disseminação, ressignificação, assimilação e "contágio" de práticas (terapêuticas, mas não apenas) "alternativas ao sistema”. Muitas dessas mediações, em sua dinâmica rizomática, deixam rastros que podem produzir muitas pequenas subversões no modelo arbóreo de estruturação das terapêuticas oficiais no âmbito dos sistemas de saúde (Deleuze e Guattari 1995).

O redirecionamento promovido pela ESF vem contribuindo significativamente para a formulação de políticas públicas e de intervenção mais eficazes para os segmentos mais carentes da população brasileira. Esse modelo trouxe modificações consideráveis para o Sistema Único de Saúde do Brasil. A partir da implantação do PACS (Programa de Agentes Comunitários de Saúde) e das propostas de humanização do sistema de saúde, implementadas na década de 1990, desenvolveram-se novas tecnologias de cuidado, como o "acolhimento" e a "visita domiciliar", e retomou-se a ideia do médico de família, visando um olhar mais amplo acerca do cuidado com o paciente (Cordeiro 1996).

Esse também é o caso de Itaparica, cujos dramas sociais da população são atravessados pelo processo de urbanização (especialmente direcionado para atender às demandas de veranistas e turistas) em contextos ditos "tradicionais" (em que se constata forte presença das religiões afro-brasileiras e evangélicas), processo este também visível em outras áreas do entorno da Baía de Todos os Santos. Este argumento é fortalecido quando enfocamos - em perspectiva histórica - questões que concernem ao uso dos serviços de saúde por essas populações desde a implantação do Sistema Único de Saúde (SUS). A expansão da oferta de atenção formal em saúde por parte do Estado, inicialmente por meio

8 A produção bibliográfica sobre a ESF no Brasil é extensa. Em linhas gerais, pode-se sugerir que essa produção mapeia questões, dificuldades, desafios e estratégias de pesquisadores comprometidos em maior ou menor grau com a proposta mais ampla desse sistema. A partir da identificação de mais de 130 trabalhos nas bases de dados Scielo e Lilacs, entre os anos de 1995 e 2008, foi possível enquadrá-los em três perspectivas de pesquisa: (a) problematizadora; (b) avaliativa/propositiva; e (c) resultados. A primeira perspectiva, que compreende poucos trabalhos, toma o contexto da ESF como objeto de reflexão a ser problematizado. A segunda engloba trabalhos comprometidos mais explicitamente com a melhoria da ESF em suas diversas dimensões e que podem envolver tanto mediadores humanos (médicos, enfermeiros, ACS, outros profissionais, gestores, equipes em geral, família, comunidades etc.) como não humanos (tecnologias materiais e instrumentais, modelos de operacionalização e gestão). $\mathrm{Na}$ última categoria, resultados, encontram-se trabalhos que buscam apresentar avaliações a partir da implementação, do impacto e da qualidade dos serviços oferecidos pela ESF (especialmente avaliações da satisfação dos usuários e consequências da implantação da ESF). O horizonte dessa produção, explicitamente situada no modelo da ESF, distancia-se, assim, dos objetivos do nosso trabalho, que busca explicitar perspectivas que geram tensionamentos nas premissas desse modelo de atenção à saúde. 
do PACS, passando pelo PSF e atualmente a ESF, não resultou necessariamente na redução do papel e importância dos saberes e práticas comunitárias em saúde, ao contrário, essas se expandem, transformam-se, contagiam-se entre si, assumindo novas formas face à crescente demanda por direitos em todos os setores da sociedade.

\section{RELIGIÃO E DIVERSIDADE TERAPÊUTICA}

Itaparica é um balneário de águas calmas e mornas que ocupa a porção norte na ilha do mesmo nome, que é a maior das 56 ilhas da Baía de Todos os Santos. Sua condição de estância hidromineral ${ }^{9}$ foi reconhecida em 1937, transformando-se em município independente em 1960, vindo posteriormente perder cerca de $75 \%$ de seu território para formar o novo município de Vera Cruz, em 1962. No centro de município e nas diversas localidades vivem pouco mais de 20.000 pessoas (20.725, segundo o Censo 2010), mas a população pode ser multiplicada no período de férias escolares e feriados prolongados. Dados do Censo 2010 indicam que a população residente é predominantemente mestiça, com $22,08 \%$ de declarantes pretos e $67,70 \%$ de pardos.

A diversidade terapêutica na ilha de Itaparica tem raízes em sua história social. Nas primeiras décadas do século passado aí eram encontrados terapeutas populares com fama para além dos limites da região e que foram objeto de trabalhos antropológicos como o de Carlo Castaldi (1955), realizado entre 1953 e 1954, que trata das atividades de três terapeutas religiosos que atuavam na ilha. Um dos terapeutas era um homem autodenominado São Venceslau, que realizava curas com uso da água de uma nascente conhecida como Poço da Sereia. Seus feitos atraíam devotos, peregrinos e pessoas em aflição de várias partes da ilha, do interior do estado e de outras partes do país. A partir da etnografia de Castaldi e cotejando com os relatos recentes de moradores da ilha, Caroso e Martins (2006, ver também Martins e Caroso 2008) revisitaram a trajetória de João Caipó, o segundo terapeuta pesquisado por Castaldi, pai de santo do candomblé que atuou na ilha entre os anos 40 e início dos anos 80 do século passado. O terceiro terapeuta citado por Castaldi é uma mãe de santo de um, à época, modesto candomblé em São João, uma pequena localidade entre Porto do Santo e Manguinhos (Caroso e Castaldi 2004, 2013; Caroso 2007, 2008). As relações que D. Lilita e sua família mantinham com o candomblé de egun da ilha podem ser identificadas em vários momentos do relato de Castaldi como, por exemplo, por ocasião de sua iniciação, que foi conduzida

9 A água mineral jorra da Fonte da Bica, construída em 1942, que tem sua nascente no Morro de Santo Antônio. O proselitismo sobre a qualidade da água e seus benefícios à saúde fez com que um historiador local (Ubaldo Osório) viesse a grafar sobre a fonte o lema: "Êta água fina, faz velha virar menina". 
por Olegário, irmão de Eduardo Daniel de Paula, fundador do terreiro "matriz" desse culto, o Omo Ilê Aboulá.

Ao discorrer sobre o candomblé na ilha de Itaparica a partir de etnografia realizada em 1975, Mendonça (1982) também aponta a falta de estudos sobre o tema, com exceção dos candomblés de egun. Sua pesquisa destaca três tradições de maior prestígio na ilha: a tradição do candomblé de egun, a herança do candomblé de Fulô, em Mar Grande, e o terreiro de João Caipó, "tido como grande curador, que além dos fundamentos religiosos possui conhecimentos médicos que alia aos primeiros em sua atividade de pai de santo" (Mendonça 1982: 92).

De fato, na tradição do candomblé, em Itaparica destacam-se até os dias atuais os candomblés de egun na região de Ponta de Areia e arredores. Os agentes de saúde e enfermeiros da ESF referem-se constantemente ao prestígio de mães e pais de santo junto à população, bem como à atuação daqueles nos cuidados em saúde, particularmente com referência à prescrição de chás, ervas para banho e outros procedimentos resolutivos, assim como encaminhamento de sua clientela aos serviços do setor profissional em saúde, quando seus pacientes apresentam manifestações físicas de doenças que julgam estar fora de sua competência terapêutica. Essa diversidade terapêutica é apontada por diversos agentes de saúde, como evidencia o relato abaixo, de Eric: ${ }^{10}$

"Então as pessoas com medo da morte, elas fazem de tudo e dentre os diversos tratamentos eles procuram as benzedeiras, que é muito comum, os pais de santo, as igrejas evangélicas que menciona muito o efeito da cura, os hospitais, postos de saúde, chás e enfim, todos esses pontos mencionados encontra-se nessa comunidade" [ACS, 48 anos, testemunha de Jeová, UBS da pista].

São evidentes as disputas entre as variantes do candomblé, especialmente no que se refere ao trabalho realizado pelos candomblés de egun. Uma conhecida mãe de santo, recentemente falecida, afirma que os trabalhos realizados no candomblé de egun são muito dispendiosos. Embora diga que suas relações com os terreiros de egun são boas, a contraposição entre o seu terreiro, que diz realizar trabalhos sem preocupação com os custos, e os de egun, foi claramente delimitada: "Ali não faz caridade não, em Babá não existe caridade". ${ }^{11}$ Além da tradição do candomblé, os raizeiros, erveiros e rezadores/

10 Exceto pelos nomes dos praticantes em saúde já referidos em outros trabalhos antropológicos, os nomes dos interlocutores na pesquisa de campo são fictícios.

11 As críticas ao candomblé também são destacadas por uma terapeuta que "recebe" o espírito de um médico e realiza consultas em sua residência em Itaparica, que afirma: "Se eu quisesse ganhar dinheiro, eu tava no candomblé e sou procurada por isso aqui, porque aqui ninguém mais acredita no pessoal de candomblé daqui, então o pessoal vem atrás de mim". 
/rezadeiras (de tradição católica, candomblé ou “autônomos") também são muito citados pelos profissionais de saúde como referências importantes para a realização de um trabalho "complementar" aos tratamentos indicados nas unidades de saúde.

Contudo, é importante destacar que a religiosidade afro-brasileira e suas variações do sincretismo afro-católico que marcam a religiosidade do município, crescentemente divide sua influência com os evangélicos pentecostais. Ao longo da última década esses segmentos têm conquistado espaços importantes no campo das práticas terapêuticas locais, especialmente em decorrência de suas características proselitistas na arregimentação de novos adeptos e consequente expansão de sua base de seguidores.

Ao compararmos os números dos censos de 2000 e 2010, fica evidente o incremento da diversidade religiosa no município, em especial o crescimento numérico das religiões evangélicas e dos "sem religião", que são tendências observadas em todo o país. ${ }^{12}$ Mas no caso de Itaparica vale destacar o crescimento dos evangélicos (especialmente as pequenas igrejas ou denominações pentecostais locais), dos espíritas e candomblecistas. No quadro l, são apresentadas as religiões que apresentam maiores percentuais de declarações.

Em consonância com um movimento que se verifica no país, no município de Itaparica pode-se observar a diminuição do número de católicos e, por outro lado, o surgimento de outras denominações religiosas. No âmbito dos

\section{Quadro 1}

Campo religioso de Itaparica

$\begin{array}{ccc}\text { Religiões em Itaparica } & \text { Censo 2000 } & \text { Censo 2010 } \\ \text { Católica Apostólica Romana } & 58,13 & 47,97 \\ \text { Evangélicas } & 13,01 & 21,34 \\ \text { Outras religiosidades cristãs } & - & 3,5 \\ \text { Testemunhas de Jeová } & 0,51 & 2,62 \\ \text { Espírita } & 0,77 & 1,6 \\ \text { Umbanda } & 0,17 & 0,1 \\ \text { Candomblé } & 1,46 & 2,62 \\ \text { Sem religião } & 17,95 & 19,13\end{array}$

Fonte: SIDRA, IBGE.

12 Ver o dossiê publicado em 2013 sobre "Censo 2010, laicidade e religiosidades populares" na revista Debates do NER, 24 (2), disponível em < http://seer.ufrgs.br/index.php/debatesdoner /issue/view/2239/showToc > (última consulta em setembro de 2015). 
evangélicos foram registradas no Censo 2010 denominações que não haviam sido detectadas pelo censo anterior: Presbiteriana, Batista e Adventista (evangélicas de missão); Assembleia de Deus, Evangelho Quadrangular, Universal do Reino de Deus e Deus é Amor (evangélicas pentecostais).

Entretanto, deve ser lembrado que as transformações religiosas são mais antigas do que o movimento captado nos dois últimos censos. Estas datam da década de 1970 e vêm alterando o cenário religioso tradicional, em que também se observa o crescimento das novas religiosidades, como a Eubiose, que tem um de seus três templos no Brasil estabelecido na cidade de Mar Grande, no município de Vera Cruz, situado na mesma ilha, que se estabeleceu no local em decorrência do significado encontrado na presença passada do Irmão Venceslau, embora este já tivesse morrido à época de sua implantação. O local de culto em que ele outrora residiu, tendo aí realizado conhecidas atividades religiosas e terapêuticas, tornou-se terra pública e área de proteção ambiental. O memorial ali existente constitui um espaço sagrado para o qual convergem praticantes de vários credos para realizar suas cerimônias e rituais variados (grupos esotéricos, membros da Eubiose, católicos, espíritas, umbandistas, candomblecistas e adeptos do xamanismo urbano), sendo o irmão Venceslau cultuado por vários desses e as águas da fonte usadas em rituais de iniciação religiosa por suas atribuídas qualidades milagrosas (Tavares, Pereira e Caroso 2011). A unidade de saúde de Porto dos Santos, em decorrência de consulta aos moradores locais feita pela administração do município, homenageia o taumaturgo que deu fama ao local até sua morte no início da década de 1960.

As transformações recentes também impactam a grande "família" do candomblé de egun, que atualmente ganha visibilidade através do ciclo de festas de Iemanjá que ocorrem no verão. Como registra Braga (1995), Ponta de Areia, que tradicionalmente foi uma comunidade de pescadores, vem experimentando marcadas transformações desde o início dos anos 70, alterando o cotidiano de sua população. Os projetos voltados para a promoção do turismo, que se intensificaram em toda a ilha nessa época, fizeram com que as populações semi-isoladas viessem a se relacionar mais assiduamente com pessoas de várias partes do país e estrangeiros que são atraídos à ilha de Itaparica.

\section{O TRABALHO JUNTO ÀS EQUIPES DE SAÚDE}

Do total de 18 estabelecimentos de saúde em Itaparica, 12 são da administração pública direta (Ministério da Saúde, Secretaria Estadual de Saúde, Secretaria Municipal de Saúde) e os restantes são unidades sob administração de empresas privadas. À época da pesquisa, em 2012, os estabelecimentos públicos de saúde compreendiam: posto de saúde (1); centro de saúde / unidade 
básica de saúde (8); hospital geral (1); clínica / centro de especialidade (1); centro de atenção psicossocial (1). ${ }^{13}$

$\mathrm{Na}$ extensa orla de Itaparica, a população residente convive com veranistas de camadas sociais diferenciadas e turistas nacionais e estrangeiros, principalmente nos distritos localizados na contracosta, banhada pelas águas do Canal do Funil, que separa a ilha da costa continental e completa o contorno sul da Baía de Todos os Santos, em sua entrada pela Ponta dos Garcez. Contrastando com a paisagem à beira-mar, o acesso à região central ou "miolo" do município é feito pela BA-001, que atravessa toda a ilha, constituindo a principal "entrada" ao município. Distribuídas nessas paisagens encontram-se as nove unidades básicas de saúde estudadas, que podem ser agrupadas em dois conjuntos: unidades da "beira-mar" e unidades da "pista". ${ }^{14}$

As unidades de saúde da "beira-mar" compreendem as regiões ou "distritos" ${ }^{15}$ banhados pelas águas da Baía de Todos os Santos e seu prolongamento no Canal do Funil e a região central do município (Centro, Ponta de Areia, ${ }^{16}$ Amoreiras, Manguinhos e Porto dos Santos). Já as unidades da pista dispõem-se às margens da rodovia BA-001 (Alto das Pombas, Misericórdia, Marcelino e Mucambo). ${ }^{17}$ Nesses bairros próximos à pista, considerados periféricos e empobrecidos, as UBS apresentam um "clima mais tenso", decorrente da maior demanda de atendimento e instalações mais precárias, do que as UBS situadas na "beira-mar".

Em consonância com as orientações do governo federal, as equipes de saúde do município são multiprofissionais. Contudo, desde o início do trabalho de campo procurámos priorizar a relação com enfermeiros e agentes de saúde, tanto pelo contato mais frequente e intenso que eles têm com a população, quanto pela dificuldade encontrada, na maioria dos casos, para se conversar com os médicos. Pelos relatos e situações observadas, os médicos estão vinculados ao espaço "dentro" das unidades, fazem visitas regulares aos postos de

13 Dados dos CNESNet, de 2012, disponíveis em < http://cnes.datasus.gov.br/Mod_Ind_Unidade. asp > (acesso em 22 de dezembro de 2012, última consulta em setembro de 2015). Esses dados foram confirmados pelo trabalho de campo, com especial destaque para a clínica / centro de especialidade recém-inaugurada à época do estudo. Esta foi considerada como uma conquista muito importante para a melhoria da atenção à saúde no município.

14 A "pista" é como os moradores locais se referem à rodovia pavimentada que corta transversalmente toda a ilha.

15 Embora na divisão territorial do município não existam distritos nem localidades rurais.

16 A unidade de Ponta de Areia ainda não opera como unidade da Saúde da Família, mas, segundo informou um profissional, em breve será convertida neste formato. Atualmente ela funciona como uma "unidade satélite", espécie de extensão da UBS de Amoreiras, tanto que o mesmo médico e enfermeira atendem nas duas localidades.

17 A unidade de Mucambo também não faz parte da Estratégia Saúde da Família. Na época da pesquisa era considerada um "posto satélite" vinculado à unidade de Misericórdia, que seria convertida em ESF. 
saúde (uma, duas ou três vezes na semana) e sabem pouco sobre as condições externas dos pacientes. As consultas são muito concorridas, sendo, portanto, muito difícil ter alguma "brecha" no atendimento para se conversar com eles. ${ }^{18}$

Merece ainda destaque a diversidade religiosa encontrada entre enfermeiros e agentes de saúde, fato que se encontra em conformidade com as principais tendências anteriormente apontadas (católicos e evangélicos pentecostais são os grupos numericamente mais expressivos em Itaparica, mas também se destacam as testemunhas de Jeová, candomblecistas e umbandistas).

\section{PREVENÇÃO, DOMESTICAÇÃO DA DEMANDA \\ E CIRCULAÇÃO DOS PROBLEMAS}

O trabalho da Estratégia Saúde da Família é marcado pela distinção valorativa em relação ao atendimento hospitalar, que pode ser caracterizada pelo fragmento de discurso de uma enfermeira transcrito abaixo:

"Então não tem como parar [de cuidar do paciente] porque PSF é isso, a gente se preocupa com o amanhã do paciente, totalmente diferente do hospital, que a gente dá alta e esquece daquele paciente, a gente não se apega ao paciente e aqui não" [Suzana, enfermeira, 31 anos, evangélica, UBS da beira-mar].

De fato, como explicita a mesma enfermeira, os cuidados em saúde que passam distantes do hospital e do atendimento emergencial são pontos fortes do modelo de intervenção característico da ESF, que busca superar a noção tradicional de cuidado fragmentado, assentado na divisão técnica do trabalho em saúde. As orientações desse novo modelo propõem um novo paradigma em saúde ancorado na qualidade de vida, onde o indivíduo encontra-se situado na relação entre família e comunidade, de cobertura universal, com o compromisso de assumir o desafio do princípio da equidade. Sua estratégia prevê um contato maior dos profissionais de saúde com as famílias, com vistas à humanização do atendimento, propondo a criação de uma relação de confiança entre a equipe de saúde e a população atendida (Almeida et al. 1999; Almeida 2001; Favoreto 2002; Senna 2002).

No contexto da unidade básica de saúde que disponibiliza atendimentos pela ESF, o equilíbrio cotidiano entre o controle da demanda e a imprevisibilidade da emergência constitui um dilema central para todos os membros da equipe, embora seja vivenciado de forma diferente pelos profissionais de "dentro" da unidade e os agentes de saúde. A organização do trabalho depende da boa administração 
desse dilema. Embora todos afirmem que o trabalho da ESF é de prevenção, em contraposição ao atendimento emergencial, característico da situação hospitalar, essas fronteiras nem sempre são claras. Um primeiro problema refere-se às ambiguidades que envolvem, ao mesmo tempo, a prevenção da demanda e a produção da demanda, como se encontra bem caracterizado abaixo.

"A Estratégia de Saúde da Família trabalha na prevenção, então nós atendemos mulheres em idade fértil fazendo planejamento familiar e aí tem uso de contraceptivo, certo? Ou distribuindo preservativo. Então nós já aqui temos a consulta, nós instruímos a pessoa, fazemos toda uma educação em saúde. [...] Até porque o planejamento familiar é uma demanda alta [...] e tá no caso orientando justamente essas questões de que tem uma demanda maior pra que as pessoas evitem, entendeu?" [Everaldo, enfermeiro, 24 anos, evangélico, UBS da pista]

Uma forma bastante disseminada de domesticação da demanda é a organização da mesma por meio de planejamento em dias escalonados para cada doença. O "atendimento" não envolve exclusivamente os pacientes, já que o trabalho é de prevenção, mas também compreende os potenciais pacientes do chamado "grupo de risco", como explicita o mesmo enfermeiro: "[A] Unidade de saúde da família é uma demanda organizada de atendimento".

Além da prevenção, também no tratamento das doenças, a estratégia é a do "convencimento", realizada pelo ACS no contexto da visita domiciliar ou em outras situações cotidianas, em que o profissional insiste na importância do tratamento preventivo (consultas e exames periódicos) dos grupos de risco, prioridades absolutas do trabalho cotidiano dos ACS, que costuma ser traduzido por "conscientização" ou "sensibilização", como se encontra posto no fragmento de narrativa abaixo do enfermeiro Everaldo:

“[...] eu não digo conscientizar, porque as pessoas por si mesmo elas se conscientizam, eu digo sensibilizar, sensibilizar aquela pessoa da importância do tratamento, entendeu? [...] Então o que eu acho principal da equipe é sensibilizar o paciente da importância daquele tratamento pra que ele mesmo... ele é a chave principal pra isso, né? Ele precisa querer fazer o tratamento, ele precisa querer ser saudável, ficar saudável novamente".

Para além da proposta da ESF, como os diferentes profissionais das equipes realizam seu trabalho cotidiano? Observa-se desafios diferentes conforme as atribuições profissionais. Quando questionados sobre suas atividades, os agentes de saúde costumam ter dificuldades em caracterizar o que fazem do ponto de vista biomédico, sendo muito generalistas quando descrevem a rotina da prevenção, orientação e encaminhamento. A mediação para a resolução entre 
os profissionais costuma provocar desafios diferentes sobre como se resolvem os problemas e o que é possível resolver. Os agentes de saúde realizam o trabalho de mediação entre a casa e a rua:

"Muitas vezes o agente de saúde não trabalha só no dia a dia na prevenção. Porque muitas vezes o agente de saúde serve como ouvidor, conselho que a pessoa possa dar. Então a gente não trabalha... a gente tá no meio da família para várias coisas. Tem pessoas que vê o [ACS] como se fosse resolver a situação deles para tudo. Então não é só a visita do dia a dia, uma prevenção não. Tem uma amizade, até muitas vezes para resolver o problema, propor um conselho que a gente possa dar" [Joceny, ACS, 43 anos, católica, UBS da pista].

Já quando se trata do trabalho dos profissionais de "dentro" das UBS, observa-se uma significativa especialização das atribuições nos contornos da intervenção biomédica, tal como se encontra nesta descrição de rotinas:

"A parte de laboratório que a gente tem aqui, um centro especializado que a gente encaminha. Passa por mim pra gente encaminhar para fazer exame de laboratório, pacientes diabéticos, hipertensos, eles vêm para a gente fazer essas consultas com eles, essa parte de enfermagem, crianças, idosos e planejamento familiar, a gente trabalha também com essa parte de prevenção com as adolescentes na fase adulta também e pré-natal" [Cândida, enfermeira, 29 anos, evangélica, UBS da beira-mar].

Embora o trabalho dos profissionais de "dentro" da UBS possa assemelhar-se mais ao atendimento "convencional", com rotinas de consultas e realização programada de exames, a prática cotidiana é atravessada por situações de emergência, pois muitas vezes o paciente vai à unidade "porque é mais próximo de casa, porque não tem dinheiro para ir a uma emergência ou às vezes foi em uma emergência, mas só que lá não resolveram o problema delas" [Lívia, enfermeira, 23 anos, católica, UBS da beira-mar].

A "prevenção", que também compreende um trabalho de "conscientização", encontra-se disseminada entre os ACS e demais membros das equipes. Realiza-se por meio de duas estratégias: a "busca ativa" dos potenciais pacientes e a realização de palestras na própria UBS, em escolas ou outros espaços coletivos. A busca ativa compreende a intervenção deliberada sobre os hábitos da população que, segundo as equipes, não favorecem os cuidados com a saúde. A não realização periódica de exames, as dificuldades em seguir os tratamentos recomendados, os problemas com a higiene e hábitos alimentares constituem "resistências" que comprometem o sucesso do trabalho. A atitude de enfrentamento cotidiano dessas resistências é muito valorizada pelos profissionais. 
Pode ser realizada através de conversas em qualquer situação social em que se encontre a pessoa, transformando-a, assim, em "paciente" potencial, ou da visita domiciliar para levar a medicação receitada, supervisionar a execução do tratamento, etc. Já os resultados das atividades de conscientização, como as "palestras", embora sejam realizadas com frequência, costumam ser questionados pelos profissionais.

No entanto, se, por um lado, os profissionais da ESF têm de lidar com a demanda dos usuários e a "controlar"; por outro, como contraparte da circulação dos ACS, temos o incremento dos problemas (e consequentemente da demanda) através da sua visibilização nas redes de cuidado. O que era restrito ao indivíduo ou ao espaço doméstico adquire existência de diversas maneiras e passa a circular. Quem identifica os problemas? A circulação nas localidades transforma as informações em problemas (passíveis de intervenção). Às vezes são os vizinhos que avisam os ACS sobre algum problema; às vezes os ACS suspeitam de algum problema e avisam a pessoa; às vezes a pessoa fala para o ACS e os familiares não sabem do problema, como por exemplo, nas situações de gravidez na adolescência.

A forma de mediação dos ACS possibilita o "surgimento" dos problemas na medida em que eles potencializam a circulação das informações. Para isso, uma série de recursos comunicativos é disponibilizada, transformando suas interações com familiares e vizinhos numa polissemia de papéis e possibilidades em aberto: "[...] temos que passar pra ele [o paciente] uma confiança, a gente tem que passar pra ele, e tudo que acontece na família fica assim entre a equipe, mais ninguém, só médico, enfermeira, as colegas de trabalho" [Neide, ACS, 38 anos, católica, UBS da beira-mar].

Mas essa forma de mediação também traz problemas ao ACS: "Porque a gente tá no dia a dia, no cotidiano dessas pessoas e a gente acaba invadindo até a privacidade deles..." [Elisângela, ACS, 33 anos, católica, UBS da beira-mar]. Além disso, constitui um dilema lidar ao mesmo tempo com as informações, já que o ACS "sabe de tudo" e tem que lidar com o controle exercido sobre ele em termos das informações.

O problema da circulação de informações constitui um desafio com o qual toda a equipe tem de lidar, ainda mais porque, no modelo de intervenção característico da ESF, também as equipes encontram-se implicadas na circulação. Assim, por vezes, os pacientes resistem a falar da doença com os ACS por temerem a "divulgação" na localidade.

\section{O QUE SÃO OS PROBLEMAS?}

Nossos interlocutores de pesquisa partilham do ideal da prevenção como estratégia eficaz de cuidado, principalmente considerando-se a situação de vulnerabilidade de grande parcela da população atendida (que compreende 
basicamente a população nativa de baixa renda). Evitar o surgimento do problema ou minimizar seus efeitos configura uma estratégia altamente valorizada pelos profissionais. No entanto, existem diferenças entre os membros das equipes na conceituação do que sejam os problemas. Para os agentes de saúde, a identificação dos problemas é mais ambígua do que entre os demais profissionais, oscilando entre o reconhecimento de sua heterogeneidade e extensão ao longo do "social" (no sentido latouriano) e o enquadramento nas definições protocolares e passíveis de intervenção pela ESF. Os agentes de saúde vivenciam de forma mais intensa (do que enfermeiros e médicos) a percepção de que as atribuições do seu trabalho seguem a extensão dos problemas. A prática cotidiana constrói diferenças importantes, como evidenciam as posições diferenciadas que são destacadas nos fragmentos de narrativas de duas provedoras de saúde citadas abaixo:

“[...] o nosso trabalho é de prevenção, de orientação e de controle. [...] tem pessoas que acham que é só relacionado à saúde, mas não é. Logo, entra muitas coisas aqui" [Neide, ACS, 38 anos, católica, UBS da beira-mar].

"Problemas sociais até que a gente acaba se envolvendo. Mas são problemas de saúde" [Eliana, enfermeira, 24 anos, católica, UBS da pista].

A concepção de saúde e doença dos profissionais enfatiza a importância dos bons hábitos de vida. Mas as ambiguidades sobre o que sejam os problemas repercutem na forma como os profissionais, especialmente os ACS, conceituam a saúde, doença e hábitos de vida: ora medicalizando os conceitos; ora deslocando-os para o contexto das relações em que esses conceitos são ressignificados. Assim, quando interpelados sobre os fatores que causam as doenças, responderam que no seu trabalho cotidiano os cuidados com a saúde não são vistos como separados dos demais cuidados (econômico, religioso, psicológico).

As ambiguidades em torno do que é o objeto de intervenção dos profissionais convivem na prática com os esforços de medicalização de hábitos considerados inadequados, intensificando suas características nocivas para a saúde da população. A dinâmica da "busca ativa" partilhada pela equipe, mas vivida intensamente pelos agentes de saúde, viabiliza passagens eficazes entre as noções de hábitos, problemas e doenças. Assim, na eclosão da doença, sobressaem, na heterogeneidade do cotidiano, as fronteiras pouco nítidas entre a "objetividade" das condições físicas e a falta de oportunidades de ascensão social - os condicionantes da saúde ${ }^{19}$ - e a dimensão voluntária das atitudes e hábitos, que podem ser alterados por meio do trabalho de convencimento. 


\section{LIDANDO COM OS PROBLEMAS:}

\section{ENTRE O ENCAMINHAMENTO E A RESOLUÇÃO}

"A unidade de saúde da família, como qualquer outra unidade, é um lugar de acompanhamento das pessoas, aqui as pessoas têm uma visão diferente do que [é] a unidade de saúde da família. Procuram a unidade de saúde da família em caso de emergência e a gente sabe que emergência não é na unidade de saúde da família. Então a gente tem tentado mudar a percepção das pessoas do que é a unidade de saúde da família" [Eliana, enfermeira, 24 anos, católica, UBS da pista].

"A gente tenta resolver o problema, porque geralmente são pessoas assim... [...] Se não tem um medicamento que é aquele de melhor escolha, a gente escolhe uma segunda opção, uma terceira opção que tenha no posto, que a pessoa não precise ter que desembolsar de qualquer forma um dinheiro para comprar, porque às vezes não tem e não tem de onde tirar. Isso aí é uma realidade" [Lívia, enfermeira, 23 anos, católica, UBS da beira-mar].

Os dois fragmentos de narrativa acima reproduzidos são de enfermeiras de unidades de saúde da pista e da beira-mar. Ambas explicitam com agudeza os dilemas envolvidos nos indicadores de resolução da ESF. Afinal, até que ponto a proposta de base, que é a prevenção e a política do encaminhamento, pode ser compreendida como resolução?

Quando questionado sobre a "resistência" ao tratamento na unidade, um ACS da pista aponta a resistência à "filosofia" do encaminhamento. As pessoas mais resistentes, no sentido apontado por ele, são aquelas menos instruídas, com "atitude primitiva" e que "não gostam de assistir palestra", como ele definiu.

A dessintonia entre o que são os problemas e as suas resoluções indica diferenças de expectativas entre os profissionais da saúde e a população. Por outro lado, mesmo entre os profissionais as ambiguidades existem: para a enfermeira do relato abaixo, as pessoas a procuram para resolver "tudo", mas quando questionada sobre o que se "resolve" no posto, verifica-se o reconhecimento da diferença entre os ideais de "resolução" e de "acompanhamento", que caracterizam o trabalho das equipes: "Não, aqui a gente só faz acompanhamento de pressão e diabete. Acompanha, orienta sobre alimentação, atividade física, sobre os medicamentos, é... tem... parte da visita domiciliar que a gente faz [...]" [Sandra, enfermeira, 32 anos, católica, UBS da beira-mar]. Mas para a enfermeira de outra unidade, o atendimento "típico" da ESF também compreende a resolução de problemas emergenciais.

Agentes comunitários, enfermeiros e médicos concordam que a forma de resolução dos problemas é o encaminhamento. Mas observam-se diferenças entre as formas de mediação que configuram o "encaminhamento". Quando 
perguntado sobre quais são os principais problemas do local, o médico de uma UBS da beira-mar destaca os problemas elencados pela ESF: doenças crônicas decorrentes de hábitos de vida inadequados. Portanto, o principal problema é a falta de prevenção.

ACS e enfermeiros sentem mais intensamente do que os médicos as ambiguidades implicadas no trabalho da ESF. Observa-se uma variação na percepção do que sejam os problemas: por um lado, são muitos os problemas com os quais o agente de saúde tem de lidar, e eles interferem nos processos de cuidados dos pacientes; por outro lado, é preciso focar nos problemas "típicos" da ESF (as doenças do "grupo de risco"), que demandam um esforço cotidiano de monitoramento através de visitas domiciliares e outros procedimentos de "busca ativa".

\section{MEDIAÇÕES E MOTIVAÇÕES DA DIVERSIDADE TERAPÊUTICA}

A importância das tradições terapêutico-religiosas, e em especial do candomblé, em Itaparica oferece um cenário com o qual as equipes da ESF têm de lidar cotidianamente. ${ }^{20} \mathrm{~A}$ diversidade terapêutica oriunda desse contexto gera controvérsias que afetam a administração dos tratamentos recomendados, mas eventuais discordâncias não se transformam em desacordos sobre a legitimidade dos tratamentos biomédicos, religiosos e/ou fitoterápicos. A diversidade de tratamentos é reconhecida pelas equipes de saúde e claramente expressa nas narrativas produzidas pelos entrevistados quando estimulados a falar da questão:

"A maioria começa a procurar lugares espirituais, vai pra religião, aí depois da religião, parte pra a crença popular, com esses medicamentos naturais que fala, né? Chazinho, erva, entre outras coisas. Aí, quando não consegue, vem pra o posto" [Jussara, ACS, 25 anos, católica, UBS da pista].

"Aqui é muito comum o uso de chá e de reza, existe rezadeiras. Tinha uma muito popular aqui na localidade, Dona B., hoje ela já não enxerga mais. E tem uma série de problemas de saúde também que a impossibilitou desse serviço prestado. Mas aqui ainda conta com algumas rezadeiras, benzedeiras, então eles procuram. Tomam chá, usam de sua sabedoria popular

20 No candomblé também se observa o reconhecimento da eficácia terapêutica no processo de cura. Mas a terapêutica das folhas é mais ampla do que a terapêutica farmacológica biomédica. Doenças e infortúnios são passíveis de tratamento ou, como salienta Serra, manifestações de "um desconforto que as folhas permitem remover" (Serra et al. 2002: 107). Isso não significa dizer que a eficácia das "folhas" se localiza no contexto ritual: nesse caso é a noção de terapêutica que é redefinida, produzindo especificidades nas relações entre eficácia terapêutica e ritual. 
e procura esse tipo de atendimento antes sim, a maioria dos casos" [Eliana, enfermeira, 24 anos, católica, UBS da pista].

Embora reconhecida, a diversidade de tratamentos nem sempre é considerada como um mediador com o qual ou contra o qual se deve lidar. No entanto, os ACS se preocupam com as eventuais consequências orgânicas e psicológicas que podem decorrer das "combinações" de tratamentos.

Uma ACS evangélica explicita em seu relato os problemas que podem surgir em consequência da filiação religiosa num contexto marcado pela forte presença do candomblé. No entanto, o problema não está situado no conflito entre concepções de tratamento, mas em possíveis interferências nas relações de confiança entre o agente e o paciente, quando passam pela mediação de pessoas que detêm certo prestígio na localidade em que o ACS também reside, como ela avalia em resposta a esta questão:

"Olha é bem complicado você mexer com a fé das pessoas, principalmente quando eles... com a crença das pessoas principalmente quando eles têm mais idade, a gente procura, assim, muito sutilmente: 'Dona Maria vá num médico, marque uma consulta pra senhora'. 'É eu vou, mas eu procurei' (eles têm mania de chamar, principalmente as mais idosas, de mãe, de pai), 'minha mãe não sei quem, meu pai não sei quem' [referindo-se às mães e pais de santo]. Principalmente quando se trata de um agente comunitário evangélico. [...] Aí complica mais ainda porque tipo: 'Ah, tá desfazendo da minha religião'" [Adélia, ACS, 45 anos, evangélica, UBS da beira-mar].

Apesar de eventuais problemas decorrentes de sua filiação religiosa na relação com outros tratamentos, para ela é preciso reconhecer os limites e potencialidades de cada terapêutica, o que significa que os dilemas configuram uma questão prática e não "ideológica". Num mundo de "repartição" das especialidades, a concorrência implica no reconhecimento das habilidades de todos.

Esses dilemas encontram ressonância na filosofia da ESF, que reformula o contexto onde são estabelecidas as relações entre os agentes de saúde e os usuários, buscando superar a percepção "tradicional" da prática médica que intervém sobre o indivíduo abstrato, remetendo-o à rede de sociabilidade na qual se encontra inserido. Tem-se, assim, entre os profissionais da ESF, uma concepção de doença que não se restringe à sua manifestação biológica, se estendendo para outros domínios da relação entre corpo, mente e ambiente, podendo se apresentar como

"Uma anormalidade, uma patologia ou disfunção orgânica ou emocional, desde quando a pessoa, ela não mais vive mais, assim, de forma harmoniosa com seu organismo, com a sua mente ou com seu estado emocional, ou até 
com sua relação interpessoal. Também isso pode ser considerado doença. [... No nosso cotidiano nós podemos entender que o que causa as doenças é o 'descuidado' com o próprio corpo ou com a mente e principalmente, pra que leve ao 'descuidado', a pouca informação. A falta de informação é algo muito..., né? É algo decisivo em relação à saúde" [Everaldo, enfermeiro, 24 anos, evangélico, UBS da pista].

Esse deslocamento é especialmente vivenciado pelos ACS em seu trabalho cotidiano, onde a extensão da doença é bem mais ampla do que sua localização corporal, envolvendo redes de parentesco e de vizinhança. Seu trabalho imiscui-se nas redes, redefinindo as fronteiras dos papéis sociais, como aponta Janaína: "Então a gente se torna agente comunitário como membro da família. Então toda questão, até mesmo pessoal, a gente acaba se envolvendo com a família. Briga, conflito, a gente acaba participando também" [ACS, 39 anos, cristã, UBS da beira-mar].

Seu trabalho encontra-se, assim, disseminado pelas redes intersticiais que atravessam os módulos territorializados de ação das equipes de saúde. Essas são redes nas quais os ACS também se encontram implicados, posto que residem nas localidades em que trabalham e costumam participar dos processos de cuidado quando ocorrem situações de emergência fora de seu horário de trabalho ou durante os finais de semana (Bonet e Tavares 2006).

\section{À GUISA DE CONCLUSÃO}

$\mathrm{Na}$ relação entre as circunstâncias e a manifestação das doenças, os profissionais apontam as doenças prevalentes da ESF como os principais problemas das localidades. No entanto, ao mesmo tempo em que cristalizam a doença como conceito, também a qualificam como evento, evidenciando os mediadores que intervêm no processo. Por outro lado, o evento da doença apresenta nuances, como se pode deduzir das narrativas de enfermeiros das UBS, que apontam as motivações pedagógicas para a transformação das condições de saúde. Entre os fatores apontados por eles se encontram a educação, boa alimentação e atividade física, disciplina e cuidado, hábitos de vida e higiene, prática de exercícios físicos e alimentação apropriada, harmonia com familiares e sociedade, todos estes fatores como podendo reduzir os riscos e consequências das doenças.

Por sua vez, para os agentes de saúde, as mediações destacadas realçam o panorama da carência vivenciada pela população como implicando fatores de risco, sendo espontaneamente mencionados o desemprego, o meio social da pessoa, as condições físicas e psicológicas, a má alimentação, conflitos em família, descaso com os cuidados da saúde.

Fazendo um paralelo entre nossos achados e as relações identificadas por Kelly (2005) entre indígenas, equipes de saúde e médicos no alto Orinoco, 
constata-se que o potencial para as controvérsias não se encontra localizado nas divergências sobre saúde e doença. As diferenças se encontram entre as intenções (deliberadas) e o "pano de fundo" (dado) sobre as quais estas adquirem motivação, sendo que as divergências não apenas fomentam as disputas e incompreensões, mas também as motivações de ambas as partes.

"Nessas circunstâncias, a orientação normal dos médicos em seu contato com os Yanomami concerne muito mais à produção de convenções para assegurar um ambiente em que se possa viver e trabalhar do que à administração de desacordos com respeito a teorias biomédicas e indígenas da doença ou a terapias. 'Instáveis', 'imprevisíveis', 'cada um faz como bem entende' são algumas das expressões empregadas para definir os Yanomami, seja como pacientes, seja como colegas de trabalho. Diante de tal entropia, os médicos gastam muito tempo e esforço em empreendimentos 'coletivizantes': estabelecendo horários, definindo regras de trabalho com o pessoal de saúde yanomami, fixando normas de acesso aos recursos da clínica” (Kelly 2005: 226).

O autor também destaca os equívocos e "desacordos homônimos" (Castro 2002) de ambas as partes em torno dos projetos para "virar civilizado":

"Eles [médicos e outros] também estão interessados em algum tipo de processo de 'virar brancos'. E, no entanto, ao passo que os Yanomami tomam a 'civilização' como uma forma de diferenciação deliberada (a produção de pessoas duais branco-indígenas, contra o pano de fundo de uma sociedade dada), missionários e médicos tomam-na como uma coletivização deliberada de um substrato entrópico: os brancos não reconhecem a existência de uma sociedade entre os índios e veem-se assim compelidos a fazer a convenção e a sociedade" (Kelly 2005: 226-227).

No caso das equipes de saúde de nossa pesquisa, talvez possamos retratar um pano de fundo de "menos" sociedade, tomando-se como medida de referência a sociedade moderna, instruída e esclarecida, apontando para uma orientação coletivizante "reformadora" dos equívocos inerentes às crenças populares e hábitos não adequados. ${ }^{21}$ Essa "falta" de sociedade é compreendida pelas equipes de saúde (e isso inclui também os ACS, a despeito de seu frequente comportamento ambíguo) como a "causa" da falta de saúde (precariedade das condições econômicas, psicológicas, emocionais e religiosas) e, ao

21 Como destaca Briggs (2003), a referência da cultura como um sistema de crenças fixas orienta as intervenções no âmbito dos programas de educação em saúde, que acabam compreendendo as diferenças como obstáculos à modificação de comportamentos. 
mesmo tempo, das dificuldades para a reversão desse quadro (já que falta educação para o remodelamento dos hábitos de vida). Essa "falta" de sociedade também pode apontar, como sugere Agier (2008), para diferentes modalidades de "pessoas" entre as populações vulneráveis, como as que não se encontram em condição de alcançar certos direitos.

Nas explicações das equipes de saúde para as dificuldades desse empreendimento civilizatório evidenciam-se ambiguidades e descompassos sobre o que as localidades "necessitam" e o que "desejam". Reconhecem, por um lado a necessidade de se melhorar as condições de vida para o incremento dos indicadores de saúde, mas ao mesmo tempo as equipes enfatizam que as mudanças de atitude é que viabilizam a aquisição da saúde; levam "informação" às comunidades (por meio de ações educativas), mas avaliam negativamente essa estratégia, admitindo a falta de interesse da população que "resiste" a esse tipo de abordagem. Assim, embora as causas das doenças sejam variáveis (fatores genéticos e outros), a responsabilidade pela doença "pertence" ao paciente como "propriedade ativa", de mentes, corpos e ação (Strathern 2006: 210).

A ambiguidade implicada nesse projeto coletivizante pode ser traduzida na homologia já destacada por Strathern:

"A pessoa ocidental, socializada e internamente controlada, precisa emergir como um microcosmo do processo de domesticação através do qual os recursos naturais se tornam disponíveis para um uso cultural. Consequentemente, a pessoa é um homólogo da sociedade pensada como um conjunto de regras e convenções" (Strathern 2006: 209).

São dilemas que atravessam a categoria "prevenção", que tanto significa a intervenção na vida da população - o que implica na percepção de pessoas destituídas de "sociedade" -, como a intervenção da população em seus corpos e mundos. 


\section{BIBLIOGRAFIA}

AGIER, Michel, 2008, Gérer les indésirables: des camps de réfugiés au gouvernement humanitaire. Paris, Flammarion.

ALMEIDA, C., 2001, "Reforma del Estado y reforma de sistemas de salud", Cuadernos Médicos Sociales, 79: 27-58.

ALMEIDA, C., et al., 1999, A Reforma Sanitária Brasileira: Em Busca da Eqüidade, Research in Public Health Technical Papers, 17. Washington, DC, OPAS.

BONET, Octavio, e Fátima Regina Gomes TAVARES, 2006, "Redes em redes: dimensões intersticiais no sistema de cuidados à saúde", em Roseni Pinheiro e Ruben Araujo de Mattos (orgs.), Gestão em Redes: Práticas de Avaliação, Formação e Participação na Saúde. Rio de Janeiro, CEPESC, 385-399.

BONET, Octavio, e Fátima Regina Gomes TAVARES, 2007, "O cuidado como metáfora nas redes de prática terapêutica”, em Roseni Pinheiro e Ruben Araujo de Mattos (orgs.), Razões Públicas para a Integralidade em Saúde: O Cuidado como Valor. Rio de Janeiro, CEPESC, 263-278.

BONET, Octavio, e Fátima Regina Gomes TAVARES, 2008, “O usuário como mediador: em busca de uma perspectiva ecológica sobre os condicionantes de saúde", em Roseni Pinheiro e Ruben Araujo de Mattos (orgs.), Cuidar do Cuidado: Responsabilidade com a Integralidade das Ações. Rio de Janeiro, CEPESQ, 191-212.

BONET, Octavio, et al., 2009, "Situação-centrada, rede e itinerário terapêutico: o trabalho dos mediadores", em Roseni Pinheiro e Paulo Henrique Martins (orgs.), Avaliação em Saúde na Perspectiva do Usuário: Abordagem Multicêntrica. Rio de Janeiro, CEPESC, 241-250 .

BRAGA, Julio, 1995, Ancestralidade Afro-Brasileira: O Culto de Babá Egum. Salvador, Editora da Universidade Federal da Bahia (Edufba).

BRIGGS, Charles L., 2003, "Why nation-states and journalists can't teach people to be healthy: power and pragmatic miscalculation in public discourses on health", Medical Anthropology Quaterly, 17 (3): 287-321.

CAMPBELL, Dave, 2010, "Anthropology's contribution to public health policy development", McGill Journal of Medicine, 13 (1): 76-83.

CAROSO, Carlos, 2007, "Carlo Castaldi: o reencontro de um naufragado com a Antropologia”, em Cláudio Pereira e Livio Sansone (orgs.), Projeto UNESCO no Brasil: Textos Críticos. Salvador, Editora da Universidade Federal da Bahia (Edufba), 185-203.

CAROSO, Carlos, 2008, "Presença do antropólogo Carlo Castaldi no Brasil: 1953 a 1958", Tempo Social, 20 (1): 297-303.

CAROSO, Carlos, e Carlo CASTALDI, 2004, "Renascimento para a santidade e a morte pela paixão: trajetória de um terapeuta religioso na iha de Itaparica, Bahia”, comunicação apresentada na XXIV Reunião Brasileira de Antropologia, Recife, PE, 12-15 de junho.

CAROSO, Carlos, e Carlo CASTALDI, 2013, "Renascido para a santidade: corporalidade, doenças, curas e milagres em Itaparica”, em Fátima Tavares e Francesca Bassi (orgs.), Para Além da Eficácia Simbólica: Estudos em Ritual, Religião e Saúde. Salvador, Editora da Universidade Federal da Bahia (Edufba), 175-202.

CAROSO, Carlos, e Rafael L. MARTINS, 2006, "Da memória etnográfica de Carlo Castaldi à memória social de João Caipó”, comunicação apresentada na XXV Reunião Brasileira de Antropologia, Goiânia, GO, 11-14 de junho de 2006. 
CASTALDI, Carlo, 1955, Religious Figures and Cults in the Recôncavo, Bahia, Brazil. Nova Iorque, University of Columbia, tese de doutoramento (não defendida).

CASTRO, Eduardo Viveiros de, 2002, "O nativo relativo", Mana, 8 (1): 113-148.

CHALLINOR, Elizabeth Pilar, 2011 , "Identidade e pertença: para além das dimensões materiais do sofrimento social”, Etnográfica, 15 (3): 479-500, disponível em < http://etnografica.revues.org/1044 > (última consulta em setembro de 2015).

CORDEIRO, H., 1996, "O PSF como estratégia de mudança do modelo assistencial do SUS", Cadernos de Saúde da Família, 1: 10-15.

CUNHA, Manuela Carneiro da, 2009, "Relações e dissenções entre saberes tradicionais e saber científico", em Manuela Carneiro da Cunha, Cultura com Aspas. São Paulo, Cosac Naify, 301-310.

DAS, Veena, 1997, "Suffering, theodicies, disciplinary practices, appropriations", International Social Sciences Journal, 154: 563-572.

DELEUZE, Gilles, e Félix GUATTARI, 1995, "Introdução: rizoma”, em Gilles Deleuze e Félix Guattari, Mil Platôs: Capitalismo e Esquizofrenia, vol. 1. São Paulo, Editora 34, $10-36$.

DELEUZE, Gilles, e Félix GUATTARI, 1997, “1440: O liso e o estriado”, em Gilles Deleuze e Félix Guattari, Mil Platôs: Capitalismo e Esquizofrenia, vol. 5. São Paulo, Editora 34, 179-214.

FASSIN, Didier, 1998, Les figures urbaines de la santé publique: enquête sur des expériences locales. Paris, La Découverte.

FASSIN, Didier, 2010, La raison humanitaire: une historie morale du temps présent. Paris, Seuil/Gallimard.

FAVOreto, Cesar Augusto Orazem, 2002, Programa de Saúde da Família no Brasil: Do Discurso e das Práticas. Rio de Janeiro, Instituto de Medicina Social da Universidade Estadual do Rio de Janeiro, dissertação de mestrado.

FONTES, Breno, 2004, "Sobre a trajetória de sociabilidade: a idéia de redes de saúde comunitária”, em Paulo Henrique Martins e Breno Fontes (orgs.), Redes Sociais e Saúde: Novas Possibilidades Teóricas. Recife, Editora da Universidade Federal de Pernambuco.

JANES, Craig R., e Kitty K. CORBETT, 2009, "Anthropology and global health", Annual Review of Anthropology, 38: 167-183.

KELLY, José Antônio, 2005, "Notas para uma teoria do "virar branco", Mana, 11 (1): 201 $-234$.

LANGDON, Esther Jean, 2014, "Os diálogos da antropologia com a saúde: contribuições para as políticas públicas”, Ciências \& Saúde Coletiva, 19 (4): 1019-1029.

LATOUR, Bruno, 2006, Changer de société: Refaire de la sociologie. Paris: Editions La Découverte.

LI, Tania Murray, 2007, The Will to Improve: Governmentality, Development and the Practice of Politics. Durham, NC, Duke University Press.

MARTINS, Rafael L., e Carlos CAROSO, 2008, "Lembranças, memórias, esquecimentos e versões: trajetória de um médico popular na ilha de Itaparica”, em Carlos Caroso (org.), Cultura, Saúde, Tecnologias e Medicinas: Perspectiva Antropológica, Salvador, Editora da Universidade Federal da Bahia (Edufba), 147-164.

MENDONÇA, Cleonice P., 1982, Santos, Orixás e Caboclos: Uma Introdução ao Mundo do Candomblé. Campinas, Universidade Estadual de Campinas (Unicamp), dissertação de mestrado em Antropologia Social. 
MOL, Annemarie, 2003, The Body Multiple: Ontology in Medical Practice. Durham, NC, Duke University Press.

PUSSETTI, Chiara, e Micol BRAZZABENI, 201 1, "Sofrimento social: idiomas da exclusão e políticas do assistencialismo”, Etnográfica, 15 (3): 467-478, disponível em < http://etnografica.revues.org/1036 > (última consulta em setembro de 2015).

SENNA, Mônica de Castro Maia, 2002, "Eqüidade e políticas de saúde: algumas reflexões sobre o programa Saúde da Família”, Cadernos de Saúde Pública, 18 (sup.): 203-21 1.

SERRA, Ordep, et al. (orgs.), 2002, O Mundo das Folhas. Feira de Santana e Salvador, Universidade Estadual de Feira de Santana e Universidade Federal da Bahia.

STrathern, Marilyn, 2006, O Gênero da Dádiva. Campinas, Universidade Estadual de Campinas (Unicamp).

TAVARES, Fátima, Cláudio PEREIRA, e Carlos CAROSO, 2011 , "Diversidade, visibilidade e dimensão pública da vida religiosa na Baía de Todos os Santos”, em Carlos Caroso, Fátima Tavares e Cláudio Pereira (orgs.), Bahia de Todos os Santos: Aspectos Humanos, tomo II. Salvador, BA, Editora da Universidade Federal da Bahia (Edufba), 479-528.

TAVARES, Fátima, e Octávio BONET, 2008, "Itinerário terapêutico e práticas avaliativas: algumas considerações”, em Roseni Pinheiro, A. Silva Júnior e R. Mattos (orgs.), Atenção Básica e Integralidade: Contribuições para Estudos de Práticas Avaliativas em Saúde. Rio de Janeiro, CEPESC - IMS/UERJ - Abrasco (Associação Brasileira de Saúde Coletiva), 189$-196$.

WAGNER, Roy, 1975, The Invention of Culture. Chicago e Londres, The University of Chicago Press. 